\title{
Mixing characteristics of refractory black carbon aerosols determined by a tandem CPMA-SP2 system at an urban site in Beijing
}

\section{Supplementary}

5 Table S1. Abbreviations and symbols used in this paper

\begin{tabular}{|c|c|}
\hline Abbreviation/symbols & Full name/explanation \\
\hline SP2 & Single particle soot photometer (DMT Technologies) \\
\hline DMA & Differential mobility analyzer (TSI Inc.) \\
\hline CPMA & Couette centrifugal particle mass analyzer (Cambustion, Ltd.) \\
\hline $\mathrm{CPC}$ & Condensation particle counter (TSI Inc.) \\
\hline \multirow[t]{2}{*}{$\mathrm{rBC}$} & Refractory black carbon determined by SP2 through laser-induced incandescence \\
\hline & method \\
\hline MED & Mass equivalent diameter \\
\hline MMD & Mass median diameter \\
\hline $\mathrm{D}_{\mathrm{p}} \& \mathrm{D}_{\mathrm{c}}$ & Diameter of rBC-containing particles and $\mathrm{rBC}$ \\
\hline LEO & Leading-edge-only fitting method \\
\hline $\mathrm{M}_{\mathrm{p}} \& \mathrm{M}_{\text {coat }} \& \mathrm{M}_{\mathrm{rBC}}$ & Mass of rBC-containing particles, mass of coating material, mass of $\mathrm{rBC}$ \\
\hline $\mathrm{M}_{\mathrm{R}}$ & $\mathrm{M}_{\text {coat }} / \mathrm{M}_{\mathrm{rBC}}$ \\
\hline Dmob & Mobility diameter determined by DMA \\
\hline$\rho_{\text {eff }}$ & Effective density \\
\hline $\mathrm{n}_{\text {coat }} \& \mathrm{n}_{\mathrm{rBC}}$ & Refractive index of coating material and $\mathrm{rBC}$ \\
\hline $\mathrm{D}_{\mathrm{fm}}$ & Mass fractal dimension \\
\hline Eabs & Absorption enhancement of $\mathrm{rBC}$-containing particles compared to bare $\mathrm{rBC}$ \\
\hline $\mathrm{SCS}_{\mathrm{sp} 2}$ & Scattering cross section of rBC-containing particles measured by SP2 \\
\hline $\mathrm{SCS}_{\text {mie }}$ & Scattering cross section of rBC-containing particles calculated using the Mie theory \\
\hline
\end{tabular}




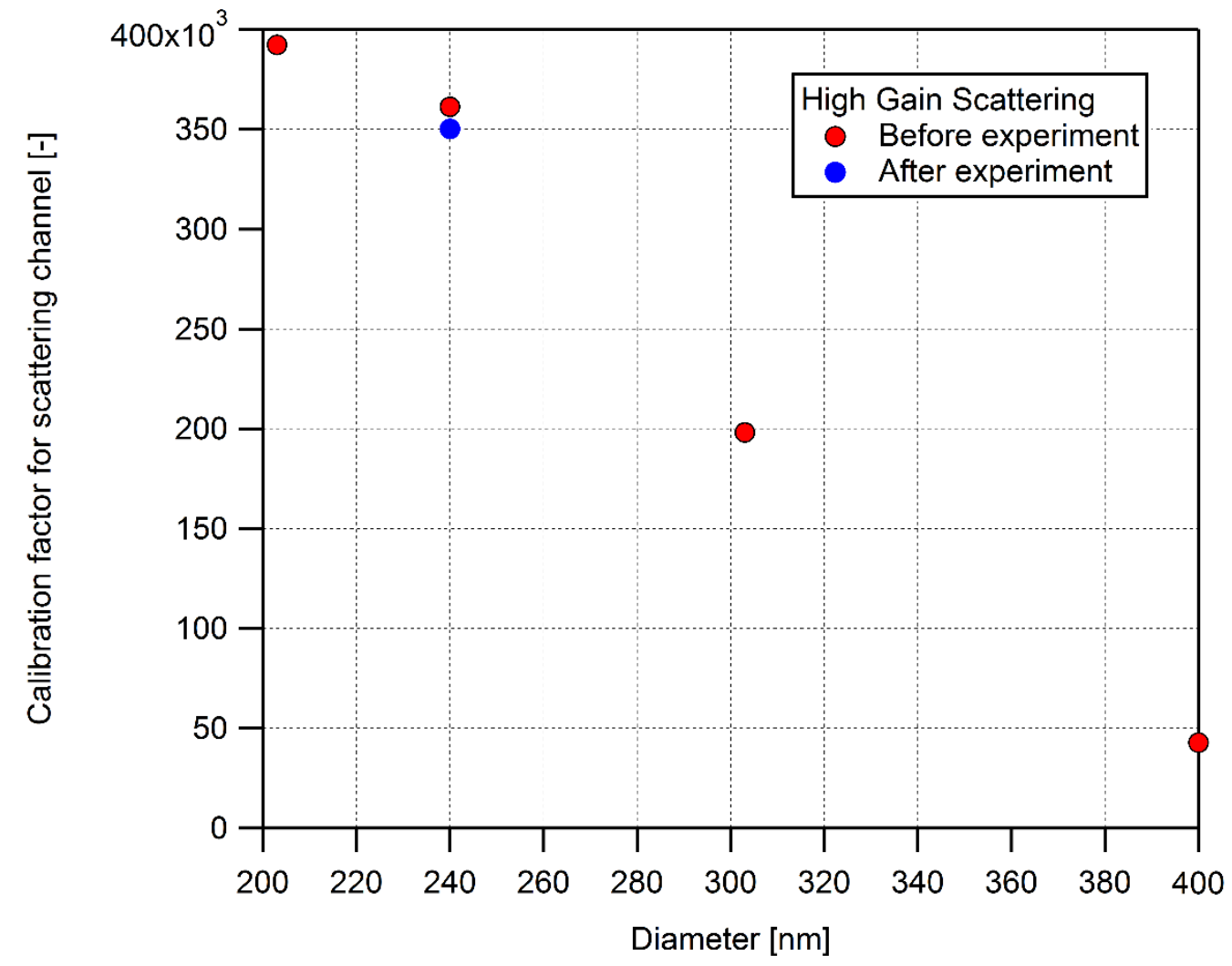

Figure S1 PSL calibration for high gain scattering channel before and after the investigation. campaign, demonstrating the stable condition for SP2).

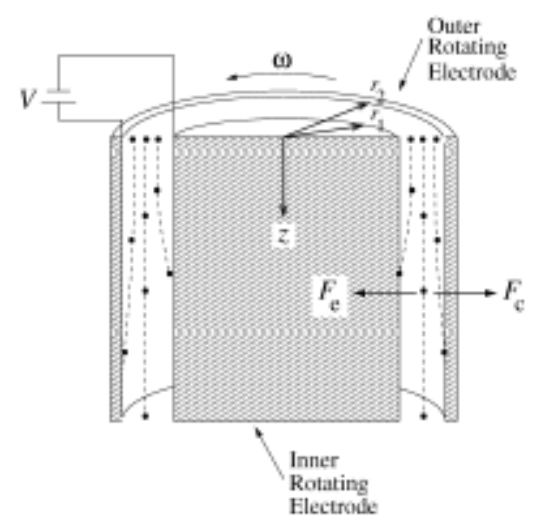




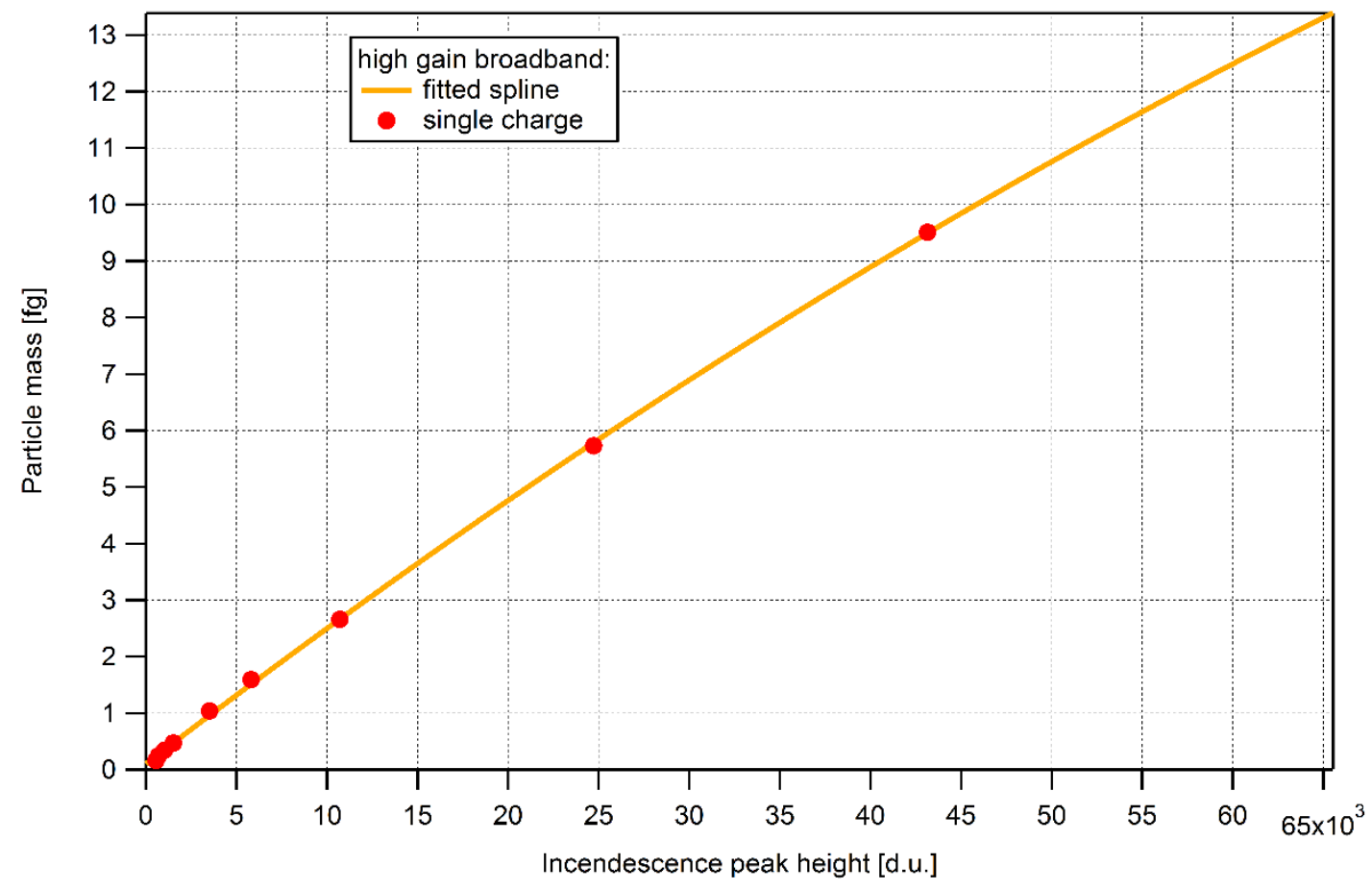

Figure S3 Calibration curve for broadband high gain channel (CPMA+SP2).

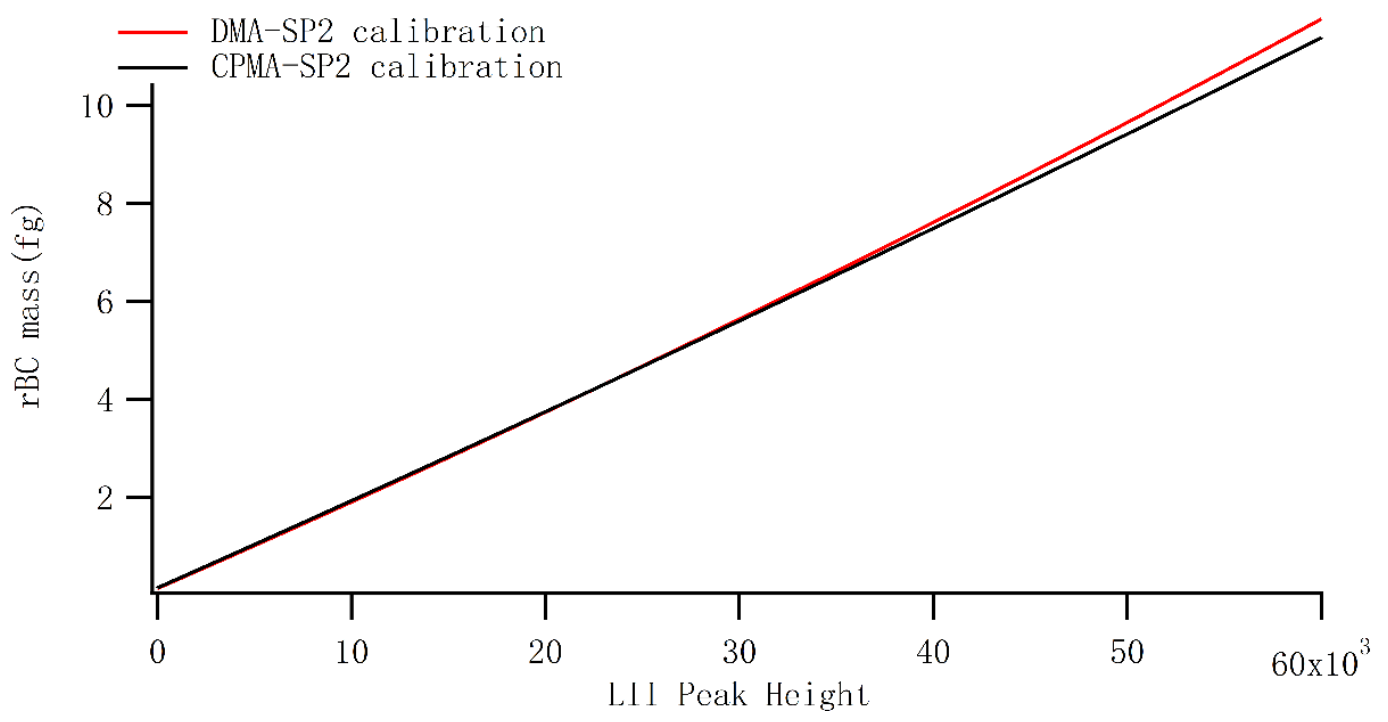

Figure S4 Comparison between CPMA-SP2 calibration factor and DMA-SP2 calibration factor. 


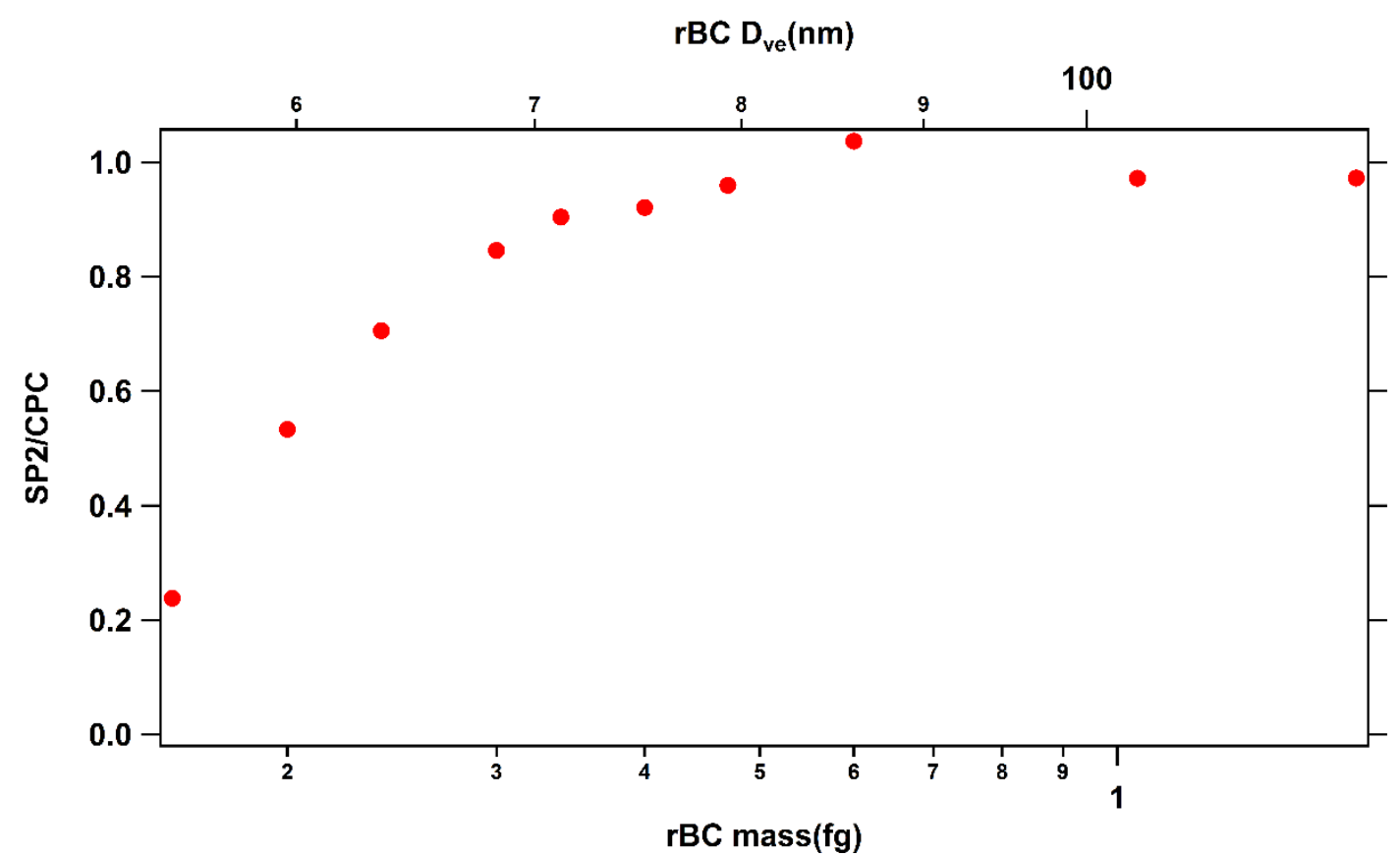

Figure S5 SP2's detection efficiency of Aquadag for a laser current of $1750 \mathrm{~mA}$.

\section{Sensitivity of refractive index and density to Mie-calculation}

The estimation of the mixing state of $\mathrm{rBC}$-containing particles was highly dependent on the parameters in the Mie scattering calculations. As shown in Table S3, previous studies adopted different parameters for the Mie calculation (Liu et al., 2014;Moteki et al., 2012; Shiraiwa et al., 2008), considering the different chemo-physical properties of rBC-containing particles in various environments. In the present study, a sensitivity test was conducted to calculate the RCT (Dp/Dc) under the assumption of different sets of parameters. The rBC-containing particles with $\mathrm{Dc}=180 \pm 10 \mathrm{~nm}$ on June 2 were selected to perform the sensitivity test. In previous studies, the refractive indices of the coatings of rBC-containing particles in a Mie-calculation were similar, ranging from $1.45-0 \mathrm{i}$ to $1.50-0 \mathrm{i}$, and the $\mathrm{rBC}$ material density ranged from 1.77 to $2.0 \mathrm{~g} / \mathrm{cm}^{3}$. However, the calculated refractive indices of the $\mathrm{BC}$ core are much different, ranging from 1.76-0.44i to 2.26-1.26i. The lower and upper bounds of the variation range were used in the sensitivity test. The parameters $\left(\mathrm{n}_{\mathrm{rBC}}=2.26-1.26 \mathrm{i}, \mathrm{n}_{\text {coat }}=1.48, \rho_{\mathrm{rBC}}=1.8 \mathrm{~g} / \mathrm{cm}^{3}\right)$ were regarded as the control group. The sensitivity experiments were performed by changing one parameter and not changing the other two parameters to calculate the RCT. As shown in Figure S8, a higher $\mathrm{n}_{\text {coat }}$ increases the scattering efficiency of coating, leading to a reduction in the deductive $\mathrm{D}_{\mathrm{p}}$ and RCT. A larger assumed $\rho_{\mathrm{rBC}}$ results in a decrease in $\mathrm{D}_{\mathrm{c}}$ as $\mathrm{D}_{\mathrm{c}}$ is inferred from $\mathrm{M}_{\mathrm{rBC}}$. According to the Mie calculation, $\mathrm{rBC}$ with a 
smaller $\mathrm{D}_{\mathrm{c}}$ core scatters less light and more scattering is attributed to coating, leading to an increase of $D_{p}$. Thus, RCT tends to increase due to the higher $D_{p}$ and lower $D_{c}$ when using a lager $\rho_{r B C}$. However, the effect of $\rho_{\mathrm{rBC}}$ and $\mathrm{n}_{\text {coat }}$ on RCT is relatively small compared to the effect of $\mathrm{n}_{\mathrm{rBC}}$. The mode of RCT significantly changes from 1 to 1.3 under different assumptions of $n_{r} \mathrm{BC}$. A larger $\mathrm{n}_{\mathrm{rBC}}$ increases the scattering efficiency of the rBC core and less scattering is attributed to coating, leading to less inverting of $\mathrm{D}_{\mathrm{p}}$ and RCT. This result is similar to (Taylor et al., 2015) in that the uncertainty in the Mie calculation caused by the refractive index of the $\mathrm{rBC}$ core is much larger than the coating refractive index and $\mathrm{rBC}$ material density.

Table S2. Different parameters from previous studies

\begin{tabular}{llll}
\hline $\mathrm{n}_{\mathrm{rBC}}$ & $\mathrm{n}_{\text {coat }}$ & $\rho_{\mathrm{rBC}}\left(\mathrm{g} / \mathrm{cm}^{3}\right)$ & References \\
\hline $2.26-1.26 \mathrm{i}$ & $1.48+0 \mathrm{i}$ & 1.8 & (Liu et al., 2014) \\
$1.95-0.79 \mathrm{i}$ & $1.48+0 \mathrm{i}$ & 1.9 & (Subramanian et al., 2010) \\
$1.76-0.44 \mathrm{i}$ & $1.52+0.015 \mathrm{i}$ & 2 & (Moteki et al., 2012) \\
\hline
\end{tabular}

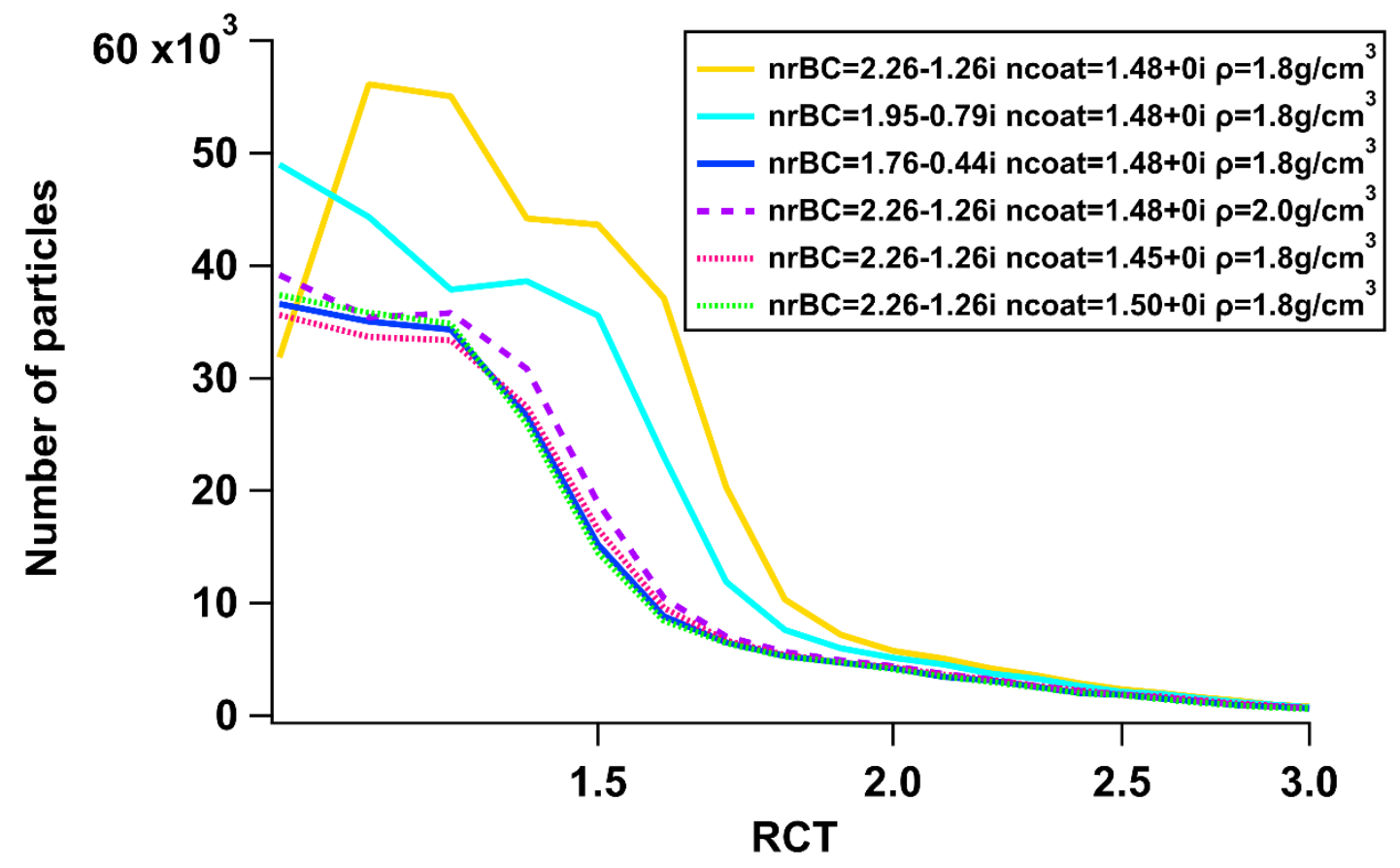

Figure S6. RCT derived from the Mie calculation under different assumptions of parameters at $\mathrm{Dc}=180 \pm 10 \mathrm{~nm}$.

When RCT is higher than 2.5, the RCT distributions derived from different $\mathrm{n}_{\mathrm{rBC}}$ tend to overlap, whereas 
calculation parameters to the RCT within different RCT ranges was evaluated as illustrated in Table 4. The RCT is first calculated using the parameters in the control group to classify rBC-containing particles into different RCT ranges, then the Mie calculation was repeatedly performed using varied parameters on particles in different RCT ranges. The sensitivity of RCT to Mie-calculation parameters presents notable dependence on RCT ranges. When the RCT is in the range of $1-1.5$, using $\mathrm{n}_{\mathrm{rBC}}=1.76-0.44 \mathrm{i}$ will result in a $21.6 \%$ overestimate of the average $\mathrm{RCT}$ compared to the average RCT derived from the control group. Such an overestimate significantly decreases to $0.5 \%$ in a RCT range of 3.5-4. A similar trend is found in the $\rho_{\mathrm{rBC}}$ sensitivity test, where the overestimate of RCT by using $\rho_{\mathrm{rBC}}=2 \mathrm{~g} / \mathrm{cm}^{3}$ also decreases with an increase in the RCT range. However, an opposite tendency appears in terms of $\mathrm{n}_{\text {coat, }}$, in which the overestimate or underestimate of RCT exhibits a positive correlation with the RCT range. In smaller RCT ranges, the $\mathrm{rBC}$ core occupies a larger fraction of the $\mathrm{rBC}$-containing particles; thus, the Mie calculation is more sensitive to the parameters related to the $\mathrm{rBC}$ core, i.e., $\mathrm{n}_{\mathrm{rBC}}$ and $\rho_{\mathrm{rBC}}$. However, with an increase in the RCT range, the $\mathrm{rBC}$ fraction decreases and the coating fraction increases, leading to greater dependence of the Mie calculation on parameters related to coatings, i.e., $\mathrm{n}_{\text {coat }}$.

\section{Determination of parameters}

In this study, a DMA+SP2 system was adopted to determine the optimal refractive indices. Ambient particles of known mobility sizes $(200 \mathrm{~nm}, 250 \mathrm{~nm}, 300 \mathrm{~nm})$ were selectively inserted into the SP2. We selected different refractive indices to calculate the optical size of ambient purely scattering particles, and the best agreement between the estimated optical size and mobility size selected by DMA was achieved when $\mathrm{n}_{\text {coat }}=1.48-0 \mathrm{i}$. This is consistent with the values $(1.5-0 \mathrm{i})$ reported in previous studies (Laborde et al., 2013;Gong et al., 2016). The difference is primarily caused by the different composition of purely scattering particles, as the refractive indices varies with composition $\left(1.51\right.$ for $(\mathrm{NH} 4)_{2} \mathrm{SO}_{4}, 1.53$ for Nacl, 1.44-1.5 for secondary organic aerosol) (Toon et al., 1976;Schnaiter et al., 2003;Nakayama et al., 2010).

(Moteki et al., 2010; Taylor et al., 2015) demonstrated that $\mathrm{n}_{\mathrm{rBC}}=2.26-1.26 \mathrm{i}$ is most suitable for the urban $\mathrm{rBC}$ that is primarily emitted by vehicles, whereas (Liu et al., 2014) hypothesized that $\mathrm{n}_{\mathrm{rBC}}=2.26-1.26 \mathrm{i}$ may not be suitable for $\mathrm{rBC}$ emitted from solid fuel. In terms of size distribution and fractal dimension, $\mathrm{rBC}$ was primarily emitted by on-road vehicles, indicating the selected $\mathrm{n}_{\mathrm{rBC}}=2.26-1.26 \mathrm{i}$ was appropriate during the summer in Beijing. The selection of $\mathrm{n}_{\mathrm{rBC}}$ is important as most of the RCT is in the range of $1-$ 

emitted from various sources; therefore, the selection of $\mathrm{n}_{\mathrm{rBC}}$ seems is complicated. However, $\mathrm{rBC}$ tends to be more thickly coated during winter, suggesting RCT is less sensitive to $\mathrm{n}_{\mathrm{r} B C}$ during winter. For simplicity, the same $\mathrm{n}_{\mathrm{rBC}}=2.26-1.26 \mathrm{i}$ value can be used in both winter and summer. However, RCT is more sensitive to $\mathrm{n}_{\text {coat }}$ when $\mathrm{rBC}$ is thickly coated. (Gong et al., 2016) reported an extremely high RCT $(\sim 2-8)$ during winter in Shanghai. The selection of $n_{\text {coat }}$ is vital in such extremely polluted cases.

Table S3. Average RCT within different RCT ranges under varied Mie-calculation parameters. (The RCT is first calculated using standard parameters to classify particles into different RCT ranges. Then, the Mie calculation is repeatedly performed using varied parameters on particles in different RCT ranges. The percentages in the brackets denote the change rate of the average RCT compared to the average RCT calculated using the standard parameters).

\begin{tabular}{|c|c|c|c|c|c|c|}
\hline & \multicolumn{6}{|c|}{ RCT range (derived from $n_{r B C}=2.26-1.26 i, n_{\text {coat }}=1.48, \rho_{r B C}=1.8 \mathrm{~g} / \mathrm{cm} 3$ ) } \\
\hline & 1-1.5 & $1.5-2$ & $2-2.5$ & $2.5-3$ & 3-3.5 & $3.5-4$ \\
\hline $\begin{array}{l}\text { RCT avg. } \\
\text { (Control) }\end{array}$ & 1.14 & 1.69 & 2.21 & 2.71 & 3.21 & 3.69 \\
\hline RCT avg. & 1.28 & 1.82 & 2.31 & 2.78 & 3.25 & 3.70 \\
\hline $\begin{array}{r}\mathrm{n}_{\mathrm{rBC}}=1.95-0.79 \mathrm{i} \\
\text { (Experiments) }\end{array}$ & $(+11.9 \%)$ & $(+8 \%)$ & $(+4.5 \%)$ & $(+2.7 \%)$ & $(+1.3 \%)$ & $(+0.5 \%)$ \\
\hline RCT avg. & 1.39 & 1.88 & 2.35 & 2.79 & 3.26 & 3.70 \\
\hline$n_{\mathrm{rBC}}=1.76-0.44 \mathrm{i}$ & $(+21.6 \%)$ & $(+11.5 \%)$ & $(+6.0 \%)$ & $(+3.3 \%)$ & $(+1.4 \%)$ & $(+0.5 \%)$ \\
\hline RCT avg. & 1.15 & 1.71 & 2.26 & 2.77 & 3.30 & 3.78 \\
\hline $\mathrm{n}_{\text {coat }}=1.45$ & $(+0.5 \%)$ & $(+1.5 \%)$ & $(+2.0 \%)$ & $(+2.3 \%)$ & $(+2.5 \%)$ & $(+2.6 \%)$ \\
\hline RCT avg. & 1.14 & 1.67 & 2.19 & 2.67 & 3.16 & 3.63 \\
\hline $\mathrm{n}_{\text {coat }}=1.5$ & $(-0.3 \%)$ & $(-0.9 \%)$ & $(-1.2 \%)$ & $(-1.4 \%)$ & $(-1.6 \%)$ & $(-1.7 \%)$ \\
\hline RCT avg. & 1.17 & 1.70 & 2.21 & 2.72 & 3.22 & 3.69 \\
\hline$\rho_{\mathrm{rBC}}=2 \mathrm{~g} / \mathrm{cm}^{3}$ & $(+2.1 \%)$ & $(+1.6 \%)$ & $(+0.8 \%)$ & $(+0.4 \%)$ & $(+0.1 \%)$ & $(0 \%)$ \\
\hline
\end{tabular}




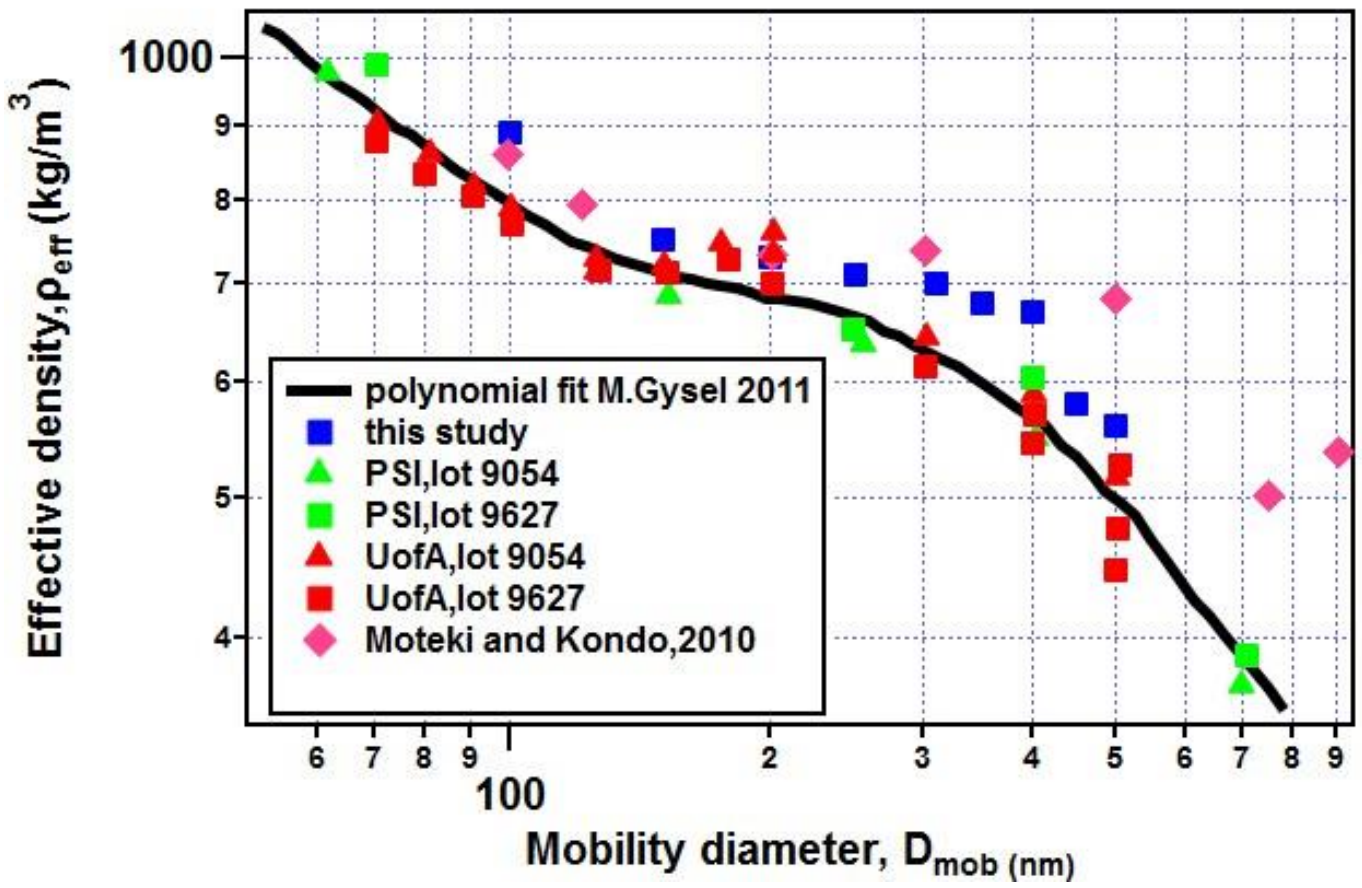

Figure S7 Relationship between effective density and mobility diameter of Aquadag measured in the present study and in previous studies.

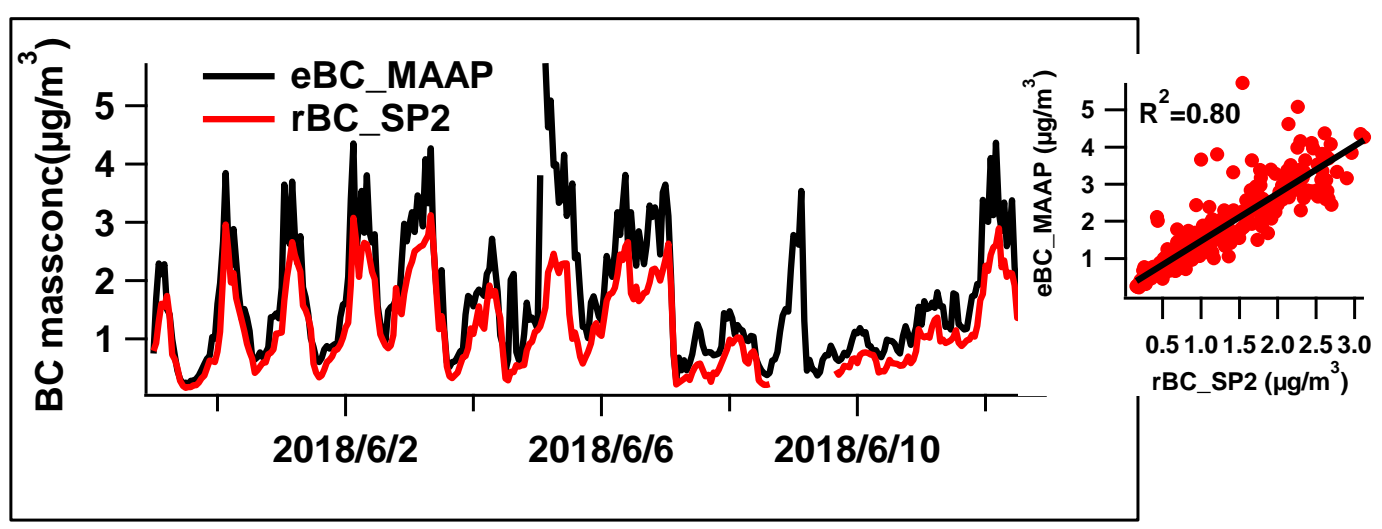

Figure S8 Comparison of the mass concentration of BC measured using MAAP and SP2. 

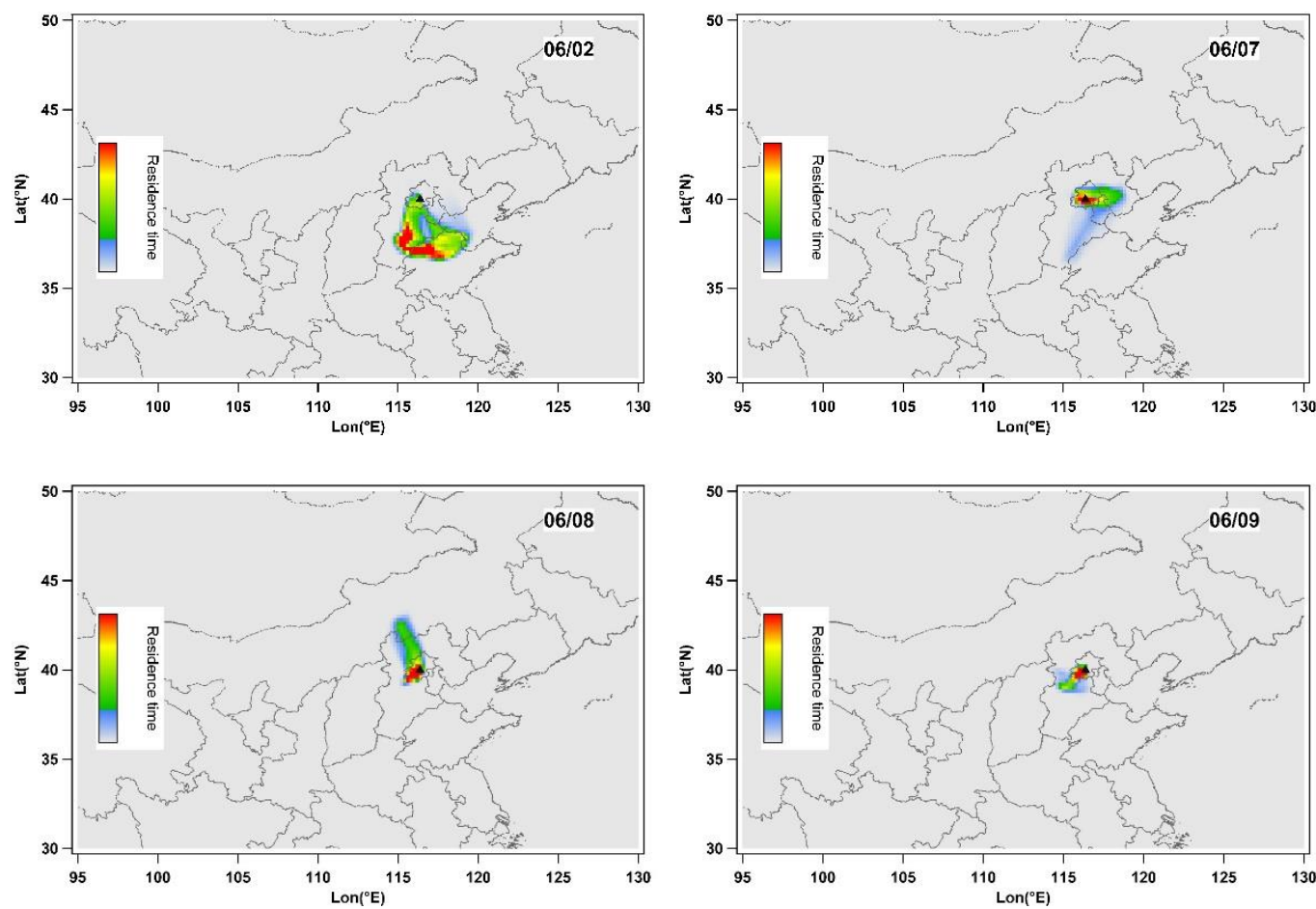

Figure S9 One-day footprints on June 2, 7,8 and 9 calculated using the FLEXPART dispersion model.

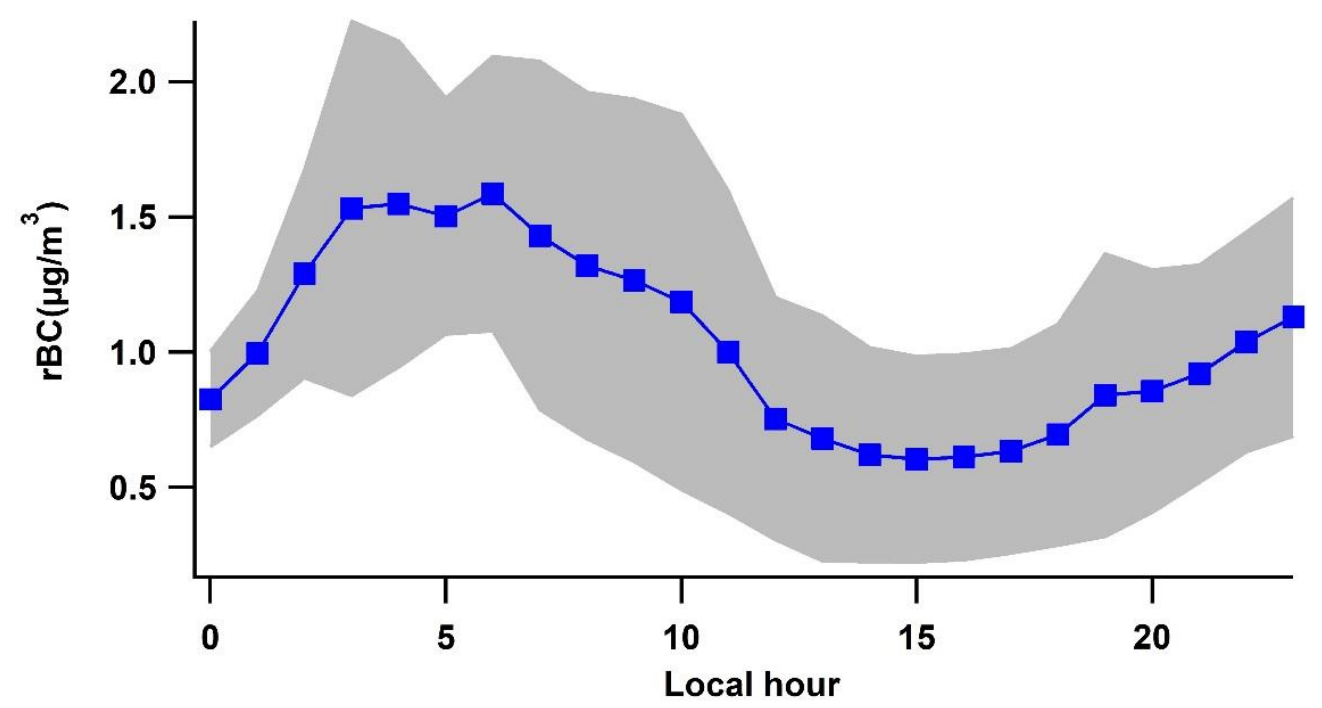

Figure S10 Diurnal variation of $\mathrm{rBC}$ mass concentration during the observation period. 


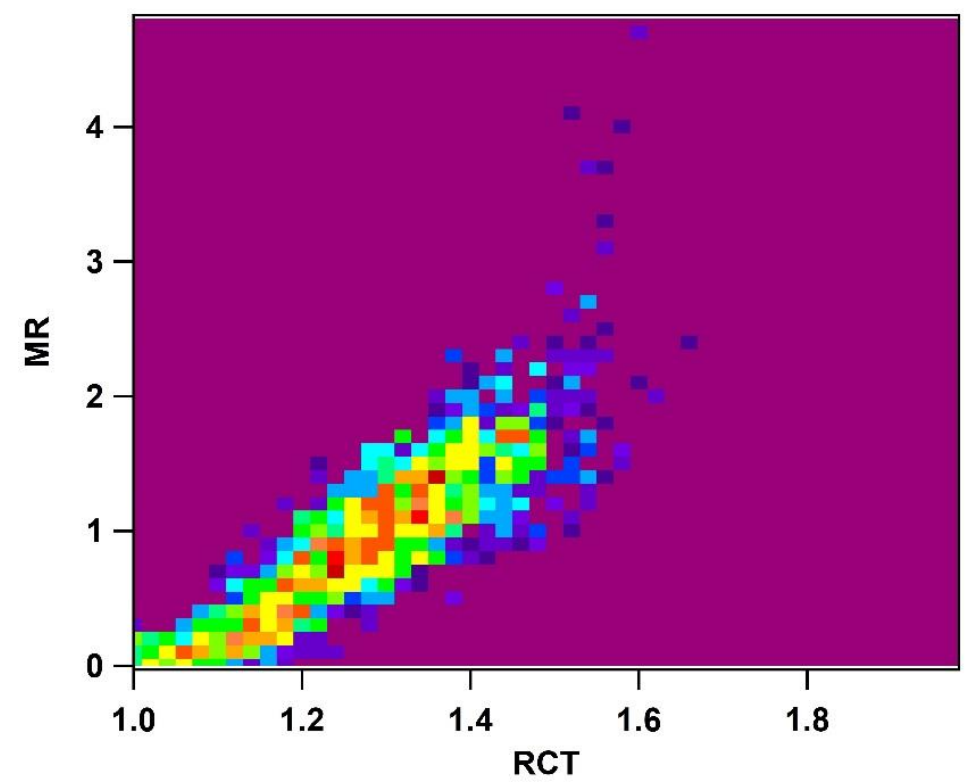

Figure S11 Dependence of the mass ratio $\left(\mathrm{MR}=\mathrm{M}_{\mathrm{coat}} / \mathrm{M}_{\mathrm{rBC}}\right)$ between the coating material $\left(\mathrm{M}_{\mathrm{coat}}\right)$ and $\mathrm{rBC}$ core $\left(\mathrm{MrBC}_{\mathrm{rB}}\right)$ as a function of $\mathrm{RCT}(\mathrm{Dp} / \mathrm{Dc})$. Colors in the plot represent the number of particles in each bin.

(a) $\mathrm{rBC}$

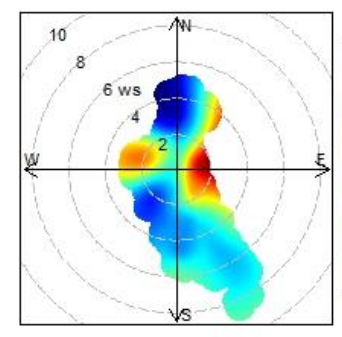

(d) $\mathrm{NO}_{2}$

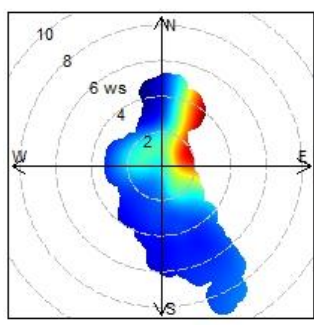

(b) Ftc

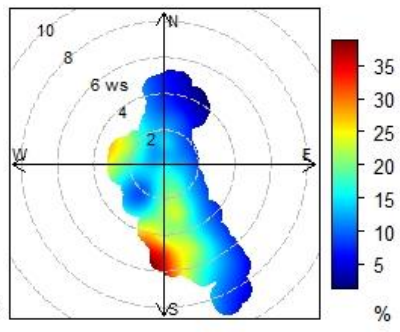

(e) $\mathrm{SO}_{2}$

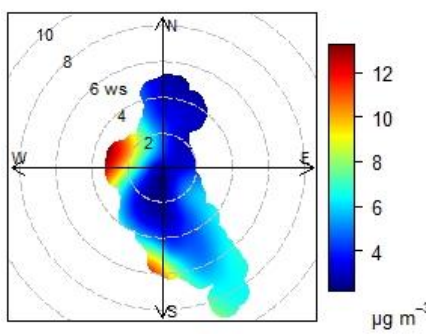

(c) MMD

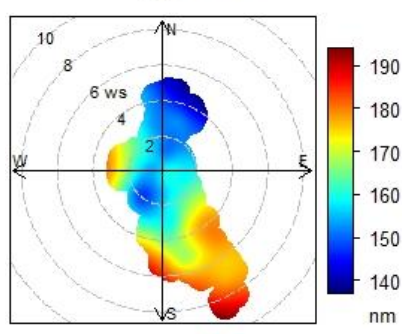

(f) $\mathrm{CO}$

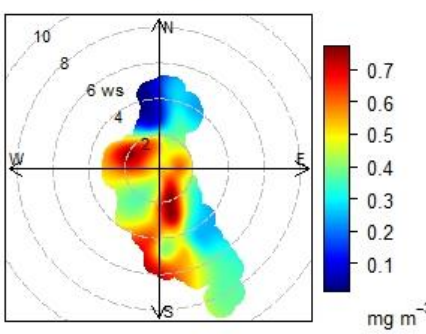

Figure S12 Dependence of rBC properties ((a) mass concentration, (b) Ftc, (c) MMD) and mass concentration ((d) NO2, (e) SO2, (c) $\mathrm{CO}$ ) on wind speed and wind direction during the investigation. 